
\title{
28 Research Suare \\ Factors associated with death in patients with tuberculosis in Brazil: survival analysis with competitive risks
}

Paulo Victor de Sousa Viana ( $\sim$ paulovictorsviana@gmail.com )

Fundacao Oswaldo Cruz https://orcid.org/0000-0002-8449-2705

Natalia Santana Paiva

Universidade Federal do Rio de Janeiro Instituto de Saúde Coletiva

Daniel Antunes Maciel Villela

Fundacao Oswaldo Cruz Programa de Computacao Cientifica

Leonardo Soares Bastos

Fundacao Oswaldo Cruz Programa de Computacao Cientifica

Ana Luiza de Souza Bierrenbach

Instituto Sirio-Libanes de Ensino e Pesquisa

Paulo Cesar Basta

Fundação Oswaldo Cruz Escola Nacional de Saúde Pública Sergio Arouca

Research article

Keywords: tuberculosis; death surveillance; survival analysis; competitive risk analysis

Posted Date: August 19th, 2019

DOI: https://doi.org/10.21203/rs.2.13108/v1

License: (9) (i) This work is licensed under a Creative Commons Attribution 4.0 International License. Read Full License 


\section{Abstract}

Background: This study aimed to analyze the factors associated with deaths caused by TB, TB-related causes and deaths from other causes. Methods: A retrospective, population-based cohort study of the causes of death, using a survival regression model in the presence of competitive risk in a cohort of patients in treatment for TB was performed using records of patients that started TB treatment in Brazil and death certificates from 2008 to 2013. Results: In this cohort, 39,997 individuals (14.1\%) died, out of a total of 283,508 individuals. Of these, 8,936 deaths due to TB $(22.4 \%), 3,365$ deaths to associated TB (8.4\%), revealing a high rate of lethality. 27,696 deaths (69.2\%) were from other causes. From our analysis, factors strongly associated with death from TB were male gender (sHR $=1.33,95 \% \mathrm{Cl}: 1.26$ 1.40), older than 60 years ( $\mathrm{sHR}=9.29,95 \% \mathrm{Cl}: 8.15-10.60)$, illiterate schooling (sHR $=2.33,95 \% \mathrm{Cl}: 2.09$ 2.59), black (sHR $=1.33,95 \% \mathrm{Cl}: 1.26-1.40)$ and brown color/race $(\mathrm{sHR}=13,95 \% \mathrm{Cl}: 1.07-1.19)$, from the southern region ( $\mathrm{sHR}=1.19,95 \% \mathrm{Cl}: 1.10-1.28)$, mixed forms ( $\mathrm{sHR}=1.91,95 \% \mathrm{Cl}: 1.73-2.11)$ and alcoholism (sHR $=1.90,95 \% \mathrm{Cl}: 1.81-2.00)$. Also, HIV positive serology was strongly associated with death due to TB (sHR $=62.78 ; 95 \% \mathrm{Cl}: 55.01-71.63)$. Conclusions: We believe that specific active surveillance strategies and early case finding could reduce mortality among tuberculosis patients, leading to a more timely detection and treatment.

\section{Background}

Although avoidable and with highly effective treatment, tuberculosis (TB) remains the ninth leading cause of death in the world and the leading cause of death among infectious diseases. In 2017, the numbers of 1.3 million deaths per TB among seronegative individuals and 300,000 deaths among HIVpositive people were estimated [1]. Although Brazil has considerably reduced the mortality and incidence rates of TB in the last decade, a significant number of deaths remains a substantial challenge for TB control in the country [2].

Identifying patients at risk of death during TB treatment should be a priority for health surveillance as it is essential for assessing programmatic needs and has the potential to contribute to the targeting of interventions and improvement of treatment monitoring [3]. In this sense, understanding the factors associated with treatment failure may allow the development of strategies to assist in more effective clinical follow-up of the individuals at risk.

Several studies have reported that factors associated with the survival of TB cases are strictly related to the presence of specific comorbidities, including HIV/AIDS and diabetes mellitus [4-10]; some clinical characteristics, such as drug resistance, default of treatment, extrapulmonary and mixed forms $[4,7,11$, 12]; to specific sociodemographic characteristics of patients (age, male gender, schooling, color or race, etc); and lifestyle, such as alcoholism and smoking $[5,8,12,13]$. In Brazil, few studies of survival analysis after TB treatment were identified in the literature $[8,14]$, which are generally regional in scope and do not address specific TB mortality, nor do they consider TB-related causes and other causes of death 
independently. It is also worth noting that the factors associated with TB deaths mentioned above have not been studied in any nationwide cohort study.

Therefore, this study aimed to analyze the factors associated with deaths caused by TB, TB-related causes and deaths from other causes, using a survival regression model in the presence of competitive risk in a cohort of patients in treatment for TB from 2008 to 2013, in all Brazilian territory.

\section{Methods}

\section{Type of study}

This is a retrospective cohort study including all patients who initiated treatment for TB in Brazil from January 1, 2008 to December 31, 2013.

\section{Study area}

Our area of study includes the entire Brazilian territory with an area of 8.5 million $\mathrm{km}^{2}$, representing $47 \%$ of the area of South America. Brazil has an estimated population of 214,190,002 in 2018, being the fifth most populous country in the world. Currently, Brazil has five macro-regions (North, Northeast, CentralWest, Southeast, and South).

\section{Data source and study population}

Two national data sources were used: The Notifiable Diseases Information System (SINAN, acronym in Portuguese) and the Mortality Information System (SIM). The SINAN database contained cases reported between January 1, 2008, and December 31, 2011, and was extracted on 09/20/2013. The SIM database contained deaths reported between January 1, 2008, and December 31, 2013, and was extracted on 04/01/16. Both databases had nominal information.

The study population consisted of all new cases of tuberculosis reported in SINAN that began treatment in the period from January 1, 2008 (date of first entry) until December 31, 2011 (date of last entry). Through record linkage of data with the SIM database, the cases were followed up until the occurrence of deaths or until December 31,2013, when administrative censoring was considered (end of the follow-up period).

These two information systems are fed continuously, have good coverage throughout the country and are decentralized to all municipalities $[15,16]$. In the particular case of TB, which has as its delineator guidelines established for case definition [15].

The variable color or race, according to the categories adopted by the Brazilian Geography and Statistics Institute (IBGE) was introduced in information systems managed by the Ministry of Health from 2000. In 
practice, the color/race variable in SINAN notification form is reported from the patient's self-declaration, based on the color of their skin, according to the five terms used by the Brazilian Institute of Geography and Statistics (or Brazilian Census Bureau, IBGE, acronym in Portuguese): white, black, brown, yellow, and indigenous $[17,18]$.

The SINAN database containing nominal identification information on TB cases reported between January 1, 2008, and December 31, 2011, was obtained on 09/20/2013.

SIM is the oldest health information system in the country, created in 1975 by the Ministry of Health to address civil registry failures. It is a system with high population coverage, which aims to record data on mortality in Brazil, comprehensively and reliably. Currently, SIM's coverage is estimated at more than $95 \%$ in Brazil [19]. Data available in the SIM is essential to understand the mortality profile of a population. It is used to calculate health indicators, perform trend analysis and to establish investment priorities in the health sector.

Death certificates are the fundamental sources for SIM. Adequate completion of the death certificate, which must necessarily be performed by physicians [20], is an essential condition for good information quality of the SIM data. Information registered in the death certificate allows adequate knowledge of the causes of death of an individual, if well completed. The term underlying cause, as defined by WHO in successive revisions of the International Statistical Classification of Diseases and Related Health Problems (ICD), refers to the "cause of death" that initiated the sequence of morbid events that led the individual to die. In addition to the underlying cause, the associated causes, which include the terminal and intermediate causes resulting from the underlying cause, as well as the causes that contributed to death without direct relation to the pathological process responsible for it, are also recorded in the death certificate.

The variable that identifies the color or race of individuals according to the categories adopted by the Brazilian Geography and Statistics Institute (IBGE) was introduced in information systems managed by the Ministry of Health in 2000. In practice, the color/race variable in SINAN notification form is reported from the patient's self-declaration, based on the color of their skin, according to the five terms used by the IBGE: Branca/white, preta/black, parda/brown, amarela/yellow, and indígena/indigenous $[17,18]$.

\section{Record linkage procedures and study groups definition}

According to the Brazilian legislation regulating access to secondary data [21], we obtained an authorization from the Ministry of Health's dedicated department (Coordenação Geral de Informação e Análise Epidemiológica-CGIEA) for the use of nominal identification data and, therefore, could performe record linkage procedures between SINAN and SIM databases for the period above.

The linkage was performed in three steps. The first one was conducted in SINAN's database using a deterministic algorithm for semi automatic linking records, similar to those validated by Pacheco et al. 
[22] and Oliveira et al. [23], with an adaptation to the STATA statistical software. The first task was preprocessing data to ensure that all variables presented the same format. For names, all letters that were upper case or doubles and had accents and different characters were removed. Suffixes such as Junior and Filho were also removed. We also removed terms that indicated the lack of knowledge about the patient's name or the patient's mother (ignored, unknown).

The second task was the removal of duplicate records in SINAN: (1) exact duplications, which are records belonging to the same individual and that relate to the same episode of illness, reported in the same health unit and (2) transfers, which are records belonging to the same patient and related to the same episode reported in different health facilities., as patient may go through several health units throughout the follow-up, in search of clinical or laboratory diagnosis and common or specialized treatment. Besides, at some point in the follow-up, hospitalization may be required. These transfers between health units can be official or spontaneous.

The second step was the linkage between the databases of SINAN and SIM. We used a probabilistic data linkage procedure using a methodology commonly applied for data encryption coding called Bloom filter [24], using the free software R 3.1.2 and package "PPRL" [25]. For this linkage, the following vital fields were employed: patient's name, mother's name, date of birth, and code of the municipality of residence. For each pair suggested in the linkage step, a score ranging from 8,600 to 10,000 was adopted. Thus, the value of the pairs near the lowest score, established as 8,600 , were less likely to be correct pairs, and those close to 10,000 were more likely to be from the same individual. After applying the Bloom filters to the identified pairs, some of them were not from the same person, mainly comprising the score range between 8,600 and 9,200 , that is, with lower scores.

Finally, in our third step, only for the groups of records found in the probabilistic data linkage between the SIM and SINAN databases, another deterministic data linkage procedure similar to that used in step one described previously was adopted, with the intention of removing from these groups false-positive for example, records not belonging to the same individual, thus increasing the specificity of the pairs found.

After the records linkage process, three analysis groups were created for the causes of death according to ICD-10 codes: i) death due to TB, those that had underlying cause with codes A15 to A19 of ICD-10; ii) associated TB deaths, those deaths in which there was no mention of any of the ICD-10 codes (A15$A 19)$, referring to $T B$ in any line of part 1 of the death certificate; iii) with no mention of TB, those deaths in which there was no mention of TB (codes A15-A19 of ICD-10) in any part of the death certificate.

\section{Inclusion and exclusion criteria}

In order to guarantee the quality of information on TB treatment episodes, an automatic surveillance routine adopted by Bierrenbach et al. [26] sought to eliminate duplicities and correct classification errors of different treatment episodes from the same patient. Thus, as shown in figure 1, excluded true duplications (records of the same patient by the same health unit and the same date of initiation of 
treatment, only the oldest, or most complete, if both had the same notification date kept). The cases classified as transference in the variable type of entry and the missing information were corrected. When the first entry was classified as "do not know" correct for a new case. Excluded records of cases terminated as a "change in diagnosis" (i.e., not TB), to analyze only the new cases in the 1st treatment entry; therefore, cases classified as return after default, relapse, and transfer were excluded. Also excluded inconsistencies in treatment starting dates and date of outcome (i.e., cases with treatment date after date of outcome), as well as missing dates (Figure 1).

\section{[INSERT FIGURE 1 HERE]}

\section{Variables of Interest}

Based on the literature review on factors associated with death among tuberculosis cases, the covariables considered in this article were: sex (female/male); schooling (illiterate, under 8 years old, over 8 years old and ignored); age group ( 0 to 19 years, 20 to 39 years, 40 to 59 years and 60 or more); color or race (white, black, brown, yellow, indigenous and ignored); macro-region (North, Northeast, Southeast, South and Central-West); clinical form (pulmonary, extrapulmonary and mixed); number of treatments (1; 2 to $3 ; 4$ or more); anti-HIV serology (positive, negative, in progress and not performed); alcoholism (yes and no); diabetes (yes and no).

\section{Statistical analysis}

The four study groups (Death due to TB, associated TB death, death with no mention of TB, and no death reported until December 31,2013) were compared in a descriptive analysis regarding the variables of interest.

Survival analysis was used to elucidate factors associated with deaths due to TB (TB as the underlying cause) considering the presence of competitive events, characterized here as the other two study groups in which individuals died (TB associated deaths, deaths with no mention of TB). The Fine \& Gray subdistribution model based on the cumulative incidence function (CIF) was used as a reference [27], considering the probability of an event occurring before a specific time. This model considers a proportional risk model for the sub-distribution of competitive risk, where the covariates directly affect the CIF. Thus, the observations on competing risks should be maintained in the range of risks. That is, for individuals in our study that died due to other causes rather than TB as the underlying cause, the model considers these risks but with a decreasing weight to take into account the reduction of the observations [28].

Survival time was measured in days comprised by the period between the entry day of treatment start and the exit day of the events of interest (TB as the underlying cause, TB associated deaths, deaths with no mention of TB) or censoring (end of follow-up on 12/31/2013). On the other hand, from the 
deterministic linkage of the data, the fatal outcomes were divided into three groups of analysis for competitive events according to the ICD-10 codes listed in part I of the death certificates and made available in the SIM.

The cumulative incidence function was used to describe the probability of TB mortality in the presence of competitive events and the Gray test was used to compare the differences between the groups. The FineGray subdistribution model was used to identify factors associated with mortality among TB cases. The first step was to use a simple risk sub-distribution model for all variables selected in this study and variables with a p-value $>0.20$ in the Wald test were removed. Then, it was produced various models with all the variables that were statistically significant in the simple model. The final model chosen was with the significant variables ( $p$-value $\leq 0.05)$ in the multiple models. The risk measure was the subdistribution hazard ratio (sHR) with its respective $95 \%$ confidence intervals. The proportionality assumption of the Fine-Gray model was initially checked for CIF and Schoenfeld residuals tests.

\section{Softwares used}

Microsoft Excel spreadsheets 2016 were used to structure the data (Microsoft Corp., Redmond, WA, USA). We conducted the statistical analysis in STATA software, College Station, TX, USA [29] and free software R version 3.3.2 (R Foundation for Statistical Computing, Vienna, Austria) in the "Survival" [30] and "Riskregression" packages [31].

\section{Ethical Considerations}

This study was approved by the Research Ethics Committee of the National School of Public Health/FIOCRUZ, under the protocol: CAAE: 14643713.0.0000.5240. The nominal identifiers were removed from the database after the data linkage, ensuring the privacy of the subjects involved in the study.

No informed consent was used since only the secondary notification data were analyzed.

\section{Results}

\section{Study population}

During the study period, a total of 283,508 subjects met inclusion criteria, including $39,997(14.1 \%)$ who died. A number of 8,936 deaths (22.4\%) were attributed to tuberculosis, 3,365 deaths ( $8.4 \%)$ had tuberculosis as an associated cause, and 27,696 deaths (69.2\%) had no mention of tuberculosis in the death certificate. Together, deaths due to TB and associated with TB summed up $30.8 \%$ of the total deaths, demonstrating a high rate of lethality in the patients under TB treatment in Brazil, between 20082013. The median follow-up of the entire cohort was 1,348 days (IQ: 949-1,761). The median elapsed 
time since treatment start for TB deaths was 27 days (IQ: 5-126), for TB associated deaths was 52 days (IQ: 9-196) and among deaths with no mention of TB was 383.5 days (IQ: 73-875).

\section{Sociodemographic and clinical characteristics}

The majority of cases $(186,777,65.9 \%)$ and most deaths $(29,322,15.7 \%)$ occurred in males, being more frequent also all causes of death among men. The most cases occurred among patients aged 20 to 39 years old. Higher death rates were observed among the oldest age group for deaths due to TB and deaths with no mention of TB ( $8.9 \%$ and $23.0 \%$, respectively). There were higher proportions of deaths due to TB $(5.2 \%)$ and deaths with no mention of TB (12.9\%) among the illiterate (Table 1).

Death rates were lower among self-reported indigenous cases $(2.8 \%$ for deaths due to TB, $0.3 \%$ for TB associated deaths, and $5.3 \%$ for deaths with no mention of TB). Most cases were from the Southeast region 129,874 (45.8\%); however, higher TB death rates were from the Central-West region (3.6\%). The southern region was the one with higher rates of deaths that had TB as an associated cause and deaths with no mention of TB $(2.2 \%$ and $11.8 \%$, respectively) (Table 1$)$.

Almost all cases (96.3\%) had been subject to a single treatment. However, higher rates of TB and TB associated deaths were observed among individuals with multiple treatments ( 4 or more) when compared to those with a single or with $2-3$ treatments $(7.3 \%$ and $6.9 \%$, respectively). While the pulmonary form was the most frequent one (82.5\%) of the total cohort, cases with "mixed forms" were the ones that died the most ( $4.6 \%$ for deaths due to TB, $5.2 \%$ for TB associated deaths, and $16.4 \%$ for deaths with no mention of TB). HIV serology was more frequent among "TB associated deaths" and "deaths with no mention of TB" (10.1\% and $23.8 \%)$, being less frequent among deaths due to TB (4.9\%) (Table 1).

For $13.5 \%$ of patients, alcohol abuse was identified, with the highest proportion of alcoholism among those that died with no mention of TB (13.4\%) and among deaths that had TB as the underlying cause $(5.2 \%)$. The presence of diabetes mellitus was reported in $5.9 \%$ of patients and was more frequent among deaths with no mention of TB (16.1\%) and deaths due to TB (4.9\%) (Table 1).

\section{[INSERT TABLE 1 HERE]}

\section{Survival Analysis}

The cumulative incidence functions for the risk sub-distribution ratio (sHR) of causes of death due to TB, associated with TB and with no mention of TB in a competitive risk structure are presented in Figure 2 . The cumulative incidence of causes of death with no mention of TB was higher than non-TB related causes and associated TB throughout the observation period, with a gradual increase of TB during the follow-up. 


\section{[INSERT FIGURE 2 HERE]}

Table 2 shows the final model with the risk sub-distribution ratio (sHR) and the $95 \%$ confidence interval $(95 \% \mathrm{Cl})$ for the covariates selected for the different causes of mortality among the reported cases of tuberculosis. The covariates were sex, age, schooling, color or race, macro-region, clinical form, anti-HIV serology, and alcoholism.

The Fine-Gray models indicated that male subjects had a higher risk of deaths due to TB (sHR: 1.33 95\% Cl: 1.26-1.40) and deaths with no mention of TB (sHR: 1.29 (95\% Cl: 1.25-1.32). The over 60 years age group was strongly associated with death in the different causal groups. For deaths due to TB and for those with no mention of TB, the sHR, as compared to the age group of $0-19$ years was $9.29(95 \% \mathrm{Cl}$ : $8.15-10.60)$ and 10.36 (95\% Cl: 9.59-11.20) respectively. The Ignored and illiterate schooling categories were strongly associated with all causes of death, presenting a risk gradient, as schooling declined. Regarding the risk of death among color or race categories, browns had a higher risk of developing death due to TB (sHR $=1.1395 \% \mathrm{Cl}: 1.07-1.19)$. Among the deaths with TB as an associated cause, the highest risk was among blacks (sHR $=1.29,95 \% \mathrm{Cl}: 1.16-1.43$ ), and a lower risk of deaths with no mention of TB was observed among indigenous and brown persons (sHR $=0.59,95 \% \mathrm{Cl}: 0.51-0.69$ and sHR $=0.96,95 \% \mathrm{Cl}: 0.93-0.99$, respectively) (Table 2).

The South and Central-West regions of the country had higher risks of death due to TB (sHR $=1.1995 \%$ $\mathrm{Cl}: 1.19-1.28)$, deaths that were associated with TB and deaths with no mention of $\mathrm{TB}$ (sHR $=0.59,95 \%$ Cl: $0.51-0.69$ and $\mathrm{sHR}=0.96,95 \% \mathrm{Cl}: 0.93-0.99$, respectively). The mixed clinical form presented higher risk of death in all categories of causes $(\mathrm{sHR}=1.91,95 \% \mathrm{Cl}$ : $1.73-2.11$, sHR $=1.62,95 \% \mathrm{Cl}$ : $1.46-1.79$; $\mathrm{SHR}=1.41 ; 95 \% \mathrm{Cl}: 1.34-1.49$, for deaths due to TB, associated with TB and with no mention of TB, respectively) (Table 2 ).

HIV positive serology showed a higher risk of death for the TB associated causes (sHR $=62.78 \mathrm{Cl} 95 \%$ : 55.01-71.63) as compared to HIV negative individuals; on the other hand, positive serology was a protective factor for deaths due to TB (sHR $=0.5995 \% \mathrm{Cl}: 0.53-0.67)$. Individuals with alcoholism comorbidity presented a higher risk among deaths due to TB (sHR $=1.90 \mathrm{Cl} 95 \%: 1.81-2.00)$ as compared to those without this comorbidity.

\section{[INSERT TABLE 2 HERE]}

\section{Discussion}

This research showed that men, people over 60 years, illiterate, black and/or brown and HIV positive, as well as living in the southern region and having mixed clinical forms and alcoholism are independent factors associated with death due to TB and death due to causes related to TB in patients who began TB treatment in Brazil in the period between 2008 and 2013. The approach of the Fine-Gray regression model, considering the presence of competing risks, revealed that there are significant changes in relative 
risks when considering three different groups of causes of death (due to TB, associated TB and with no mention of TB) among patients undergoing treatment for TB in a cohort of approximately 300,000 people throughout the national territory.

We understand that classical survival analysis is not appropriate when the object of interest is to analyze the elapsed time from an initial event to the occurrence of complex events, such as the existence of competitive events, where the individual may be at risk for more than one cause of events, such as the various causes of death studied here. One of the alternatives to analyze the data in the presence of competitive events is the Fine-Gray sub-distribution model of risk that has proved useful in the analysis of the factors associated with death for cases under treatment for TB in Brazil.

Death due to TB is considered a sentinel event which should have been prevented, as the disease has a rather straightforward diagnosis, there are available free medications in the public health network throughout the country, the complete treatment with first-line drugs is relatively inexpensive and the disease is curable in almost $100 \%$ of cases. Therefore, the high number of deaths analyzed here points to weaknesses in the model of care offered to these patients. These frailties range from difficulties in access to diagnosis and treatment in the primary care services to access to emergency services and hospitalization for patients with advanced stages of illness [32].

As reported elsewhere [33-35], in this study we identified a high risk of death during treatment, especially among men. Among the explanations for the additional risk of death in men is the lower predisposition to adherence to treatment regimens [36] and a lifestyle that includes excessive use of alcohol and tobacco, as well as malnutrition when compared to women $[37,38]$.

In this analysis, individuals aged 60 years or older had a higher chance of death in the different causes analyzed. Similar results have been described by other authors $[34,39]$ The fact that TB in older individuals significantly increases the chances of death should be considered when following up these patients throughout their treatment. The coexistence of other diseases related to old age may be associated with late diagnosis of TB due to atypical clinical presentation of the symptoms or the development of extra-pulmonary forms hard to diagnose, which can complicate the clinical picture and increase the risk of evolution to death.

Interestingly, although the incidence of TB in indigenous populations is consistently higher than that observed among the general population, as reported by several authors [40-42], both the number (absolute and proportional) and the risk of death among self-classified indigenous patients were lower when compared to other color or race categories. Thus, this finding is consistent with other studies that analyzed SINAN's reporting data, with emphasis on the variable outcome, in local or regional contexts [41] $[42,43]$. On the other hand, these data may be hiding difficulties for an adequate follow-up of TB cases under treatment, especially in the most isolated areas of the country, where most of the Indigenous Lands are. 
Although the concept of race is widely recognized as a social construct, it represents an important indicator of health and is mostly based on a social definition of race, rather than on a biological or genetic characterization. It is worth noting the higher chances of death due to TB and associated TB among individuals classified as "black" and "brown" as compared to "white". The identification of racial groups at higher risk is crucial for Tuberculosis Control Programs which should lead to the development of differential strategies of follow-up, in an attempt to close the historical, sociological, socioeconomic and access to health services gaps $[18,44]$.

TB is the most common opportunistic infection, and several studies have shown that it is the leading cause of death among people living with HIV/AIDS [45, 46], accounting for approximately $25 \%$ of HIV/AIDS deaths. In this analysis, similar to other studies [13, 39], a 62-fold higher risk of TB death was identified among seropositive patients who started TB treatment. The fact that there were 319 HIV positive individuals that died due to TB and not due to AIDS with TB as an associate cause in our cohort probably reflects misclassification of cause of death errors.

The association between TB and diabetes mellitus (DM) is well established [47]. There is evidence indicating that DM contributes significantly to increasing the incidence of TB and is associated with higher chances of death during treatment $[48,49]$. The convergence between the TB and DM epidemics can have severe implications for achieving the goal of $95 \%$ reduction in TB mortality by 2035 , as established in the End TB strategy [50]. The findings of this study suggest the need for better screening of DM in patients with TB in order to avoid unfavorable outcomes such as death.

The prevalence of alcohol abuse disorders in Brazil is around 13.7\% in the adult population [51]. In our study, based on information contained in the notification forms, the prevalence of alcoholism among patients reached $13.5 \%$. Alcohol abuse has been recognized as a relevant risk factor for death among cases starting treatment for TB [52] [53].

Record linkage between SINAN and SIM databases is a widely used strategy to identify underreporting of TB cases and TB deaths in Brazil $[26,54]$. In our study, this method allowed us to identify deaths that were not captured in the follow-up of the treatment cohort, as previously reported by other authors [54, 55]. However, since in our methodology there was an initial probabilistic linking stage with high sensitivity/low specificity performed by the Ministry of Health staff with the total mortality database and we, the researchers, only had access to death records that had been linked to TB records in this stage, it was not possible to have access to the totality of deaths that occurred in Brazil between 2008 and 2013. Thus, it was only possible to seek complementary information in the death certificate of patients enlisted in the TB notification registry (SINAN). Unlike other studies with similar approaches [56], in our study, it was not possible to estimate the underreporting of TB cases by recovering deaths that were caused by or associated with TB as reported in the death certificate and that had not been reported to SINAN.

Despite the illustrative findings and the national scope of this study, it is important to take some limitations into account. As with any study based on secondary reporting data, there may have been underreporting cases and/or deaths, the incompleteness of some variables, errors in classification and/or 
coding of cases. Misclassification errors may have particularly occurred for causes of death in the death certificates and as regards to the variables color or race.

In our analyses, we included 266,668 cases. On the one hand, the survival estimates presented here, in the presence of competitive events, identified significant differences in death risks with notable statistical significance and narrow confidence intervals. On the other hand, due to the large size of the sample, the standard errors became extremely small; however, the associations found in this study show biological plausibility and are widely recognized in the literature, so that we do not consider our results to be unfeasible.

Finally, our findings indicate that TB or TB associated deaths occurred early in the first weeks of treatment, with median times of 27 and 52 days, respectively, while deaths due to other causes occurred at a median time of more than a year since treatment start, when most patients would have finished their treatment. This result indicates that patients were probably diagnosed with TB late at an advanced stage of the disease. This situation is perhaps related to the high rate of lethality reported here. Early diagnosis is key to a favorable outcome as established in the literature [57].

If we consider that TB or TB associated deaths were strongly associated with males, advanced age, illiterates, individuals of black/brown color, those who presented mixed clinical forms and were patients with HIV and suffering from alcoholism, it is possible to assume that if there was active surveillance of the cases being treated, together with strategies for early detection and adequate follow-up of the patients, the specific mortality due to tuberculosis could be reduced.

\section{Conclusion}

In conclusion, our findings reinforce the social character of TB by revealing the most vulnerable groups of TB patients at risk of dying of this curable disease in Brazil. According to Pillar number 2 of the WHO EndTB Strategy, there is a need for sustained efforts by the health sector to control the disease. It is necessary to invest in bold policies to reduce social inequalities and health disparities in order to end TB as a public health problem in the country and the world until the year 2035.

\section{Abbreviations}

\section{AIDS - Acquired immunodeficiency syndrome}

\section{CGIEA - Coordenação Geral de Informação e Análise Epidemiológica}

\section{Cl- Confidence interval}

\section{CIF - Cumulative Incidence Function}


DM-Diabetes mellitus

IBGE - Brazilian Geography and Statistics Institute

ICD - International Statistical Classification of Diseases and Related Health Problems

IQ - Interquartile range

HIV - Human immunodeficiency virus

SHR - Subdistribution Hazard Ratio

SIM-Mortality Information System

SINAN - The Notifiable Diseases Information System

$T B$-Tuberculosis

WHO-World Health Organization

Declarations

Ethics approval and consent to participate

This study was approved by the Research Ethics Committee of the National School of Public Health/FIOCRUZ, under the protocol: CAAE: 14643713.0.0000.5240. The nominal identifiers were removed from the database after the data linkage, ensuring the privacy of the subjects involved in the study.

Consent for Publication

Not applicable

Availability of data and material 
Data supporting the results of this study are available from the Brazilian National Tuberculosis Program, but restrictions apply to the availability of such data through the Access to Information Law and are therefore not publicly available. However, the data are made available by the authors upon justifiable request and with authorization from the Brazilian National TB Program. The request should be performed through the URL: http://www.acessoainformacao.gov.br/sistema/site/primeiro_acesso.html.

\section{Competing interests}

The authors declare that they have no competing interests.

\section{Funding}

Not applicable

\section{Authors' contributions}

PVSV, ALSB and PCB, participated in formulating the research concept and design. PVSV, NSP and ALSB conducted statistical analyses. PVSV, NSP, DAMV, LSB, ALS and PCB wrote the manuscript and commented on the manuscript. The final paper submitted for publication was read and approved by all authors.

\section{Acknowledgements}

The Brazilian Ministry of Health and the National Tuberculosis Control Program (PNCT) for the availability of data, especially Maria de Fatima Marino de Souza, Denise Arakaki-Sanchez, Patricia Barthlomay and Danielle Pelissari. Noteworthy is the important support of Antony Stevens in one of the stages of database linkage. The support and assistance offered by the Graduate Program in Epidemiology in Public Health of the National School of Public Health (ENSP) under the coordination of Leticia Oliveira Cardoso and the administrative support provided by Marcella Fagundes and Joyce Torres. thank you all very much!

\section{References}

1. WHO. Global Tuberculosis Report 2018. Geneva, Switerzeland: World Health Organization; 2018.

2. BRASIL. Implantação do Plano Nacional pelo Fim da Tuberculose como Problema de Saúde Pública no Brasil: primeiros passos rumo ao alcance das metas. Brasília; 2018.

3. BRASIL. Protocolo para vigilância do óbito com menção de tuberculose nas causas de morte. Brasília: Ministério da Saúde. Secretaria de Vigilância em Saúde. Departamento de Vigilância das Doenças Transmissíveis.; 2017. 
4. Adamu AL, Aliyu MH, Galadanci NA, Musa BM, Gadanya MA, Gajida AU, et al. Deaths during tuberculosis treatment among paediatric patients in a large tertiary hospital in Nigeria. PLoS One. 2017;12:e0183270.

5. Lo H-Y, Suo J, Chang H-J, Yang S-L, Chou P. Risk factors associated with death in a 12-month cohort analysis of tuberculosis patients: 12-month follow-up after registration. Asia Pac J Public Health. 2015;27:NP758-68.

6. Chung-Delgado K, Guillen-Bravo S, Revilla-Montag A, Bernabe-Ortiz A. Mortality among MDR-TB cases: comparison with drug-susceptible tuberculosis and associated factors. PLoS One. 2015;10:e0119332.

7. Nahid P, Jarlsberg LG, Rudoy I, de Jong BC, Unger A, Kawamura LM, et al. Factors associated with mortality in patients with drug-susceptible pulmonary tuberculosis. BMC Infect Dis. 2011;11:1.

8. Albuquerque M de FPM de, Batista J d'Arc L, Ximenes RA de A, Carvalho MS, Diniz GTN, Rodrigues LC. Risk factors associated with death in patients who initiate treatment for tuberculosis after two different follow-up periods. Rev Bras Epidemiol. 2009;12:513-22.

9. Bernabe-Ortiz A. Factors associated with survival of patients with tuberculosis in Lima, Peru. Rev Chilena Infectol. 2008;25:104-7.

10. Shuldiner J, Leventhal A, Chemtob D, Mor Z. Mortality after anti-tuberculosis treatment completion: results of long-term follow-up. Int J Tuberc Lung Dis. 2016;20:43-8.

11. Low S, Ang LW, Cutter J, James L, Chee CBE, Wang YT, et al. Mortality among tuberculosis patients on treatment in Singapore. Int J Tuberc Lung Dis. 2009;13:328-34.

12. Mathew T a, Ovsyanikova TN, Shin SS, Gelmanova I, Balbuena D a, Atwood S, et al. Causes of death during tuberculosis treatment in Tomsk Oblast, Russia. Int J Tuberc Lung Dis. 2006;10:857-63.

13. Horne DJ, Hubbard R, Narita M, Exarchos A, Park DR, Goss CH. Factors associated with mortality in patients with tuberculosis. BMC Infect Dis. 2010;10:258.

14. Maruza M, Albuquerque MFPM, Braga MC, Barbosa MTS, Byington R, Coimbra I, et al. Survival of HIV-infected patients after starting tuberculosis treatment: a prospective cohort study. Int J Tuberc Lung Dis. 2012;16:618-24.

15. BRASIL. Guia de vigilância epidemiológica. 7th edition. Brasília: Ministério da Saúde, Secretaria de Vigilância em Saúde, Departamento de Vigilância Epidemiológica; 2009.

16. Laguardia J, Domingues CMA, Carvalho C, Lauerman CR, Macário E, Glatt R. Sistema de Informação de Agravos de Notificação ( Sinan): desafios no desenvolvimento de um sistema de informação em saúde. Epidemiol e Serviços Saúde. 2004;13:135-47.

17. Monk EP. The Consequences of "race and Color" in Brazil. Soc Probl. 2016;63:413-30.

18. Travassos $C$, Williams $D$. The concept and measurement of race and their relationship to public health: a review focused on Brazil and the United States. Cad Saude Publica. 2004;20:660-78.

19. Lima EEC de, Queiroz BL. Evolution of the deaths registry system in Brazil: associations with changes in the mortality profile, under-registration of death counts, and ill-defined causes of death. 
Cad Saude Publica. 2014;30:1721-30.

20. BRASIL. A Declaração de Óbito: documento necessário e importante. 3rd edition. Brasília: Ministério da Saúde, Conselho Federal de Medicina, Centro Brasileiro de Classificação de Doenças; 2009.

21. Santo $A H$, Pinheiro $C E$, Jordani MS. Causas múltiplas de morte relacionadas à tuberculose no Estado de São Paulo, 1998. Rev Saude Publica. 2003;37:714-21.

22. Pacheco AG, Saraceni V, Tuboi SH, Moulton LH, Chaisson RE, Cavalcante SC, et al. Validation of a hierarchical deterministic record-linkage algorithm using data from 2 different cohorts of human immunodeficiency virus-infected persons and mortality databases in Brazil. Am J Epidemiol. 2008;168:1326-32.

23. Oliveira GP de, Bierrenbach AL de S, Camargo Júnior KR de, Coeli CM, Pinheiro RS. Accuracy of probabilistic and deterministic record linkage: the case of tuberculosis. Rev Saude Publica. 2016;50:1-9.

24. Schnell R, Bachteler T, Reiher J. Privacy-preserving record linkage using Bloom filters. BMC Med Inform Decis Mak. 2009;9:41.

25. Schnell R, Rukasz D. PPRL: Privacy Preserving Record Linkage. 2019;:1-13. doi:.1037//00332909.126.1.78.

26. Bierrenbach AL, de Oliveira GP, Codenotti S, Gomes ABF, Stevens AP. Duplicates and misclassification of tuberculosis notification records in Brazil, 2001-2007. Int J Tuberc Lung Dis. 2010;14:593-9.

27. Fine JP, Gray RJ. A Proportional Hazards Model for the Subdistribution of a Competing Risk. J Am Stat Assoc. 1999;94:496-509.

28. Gray RJ. A Class of K-Sample Tests for Comparing the Cumulative Incidence of a Competing Risk. Ann Stat. 1988;16:1141-54.

29. StataCorp. Stata Statistical Software: Release 13. 2015.

30. Therneau T. A Package for Survival Analysis in R. 2015. http://cran.r-project.org/package = survival.

31. Gerds TA, Ozenne B. riskRegression: Risk Regression Models and Prediction Scores for Survival Analysis with Competing Risks. 2019. https://cran.r-project.org/pack age = riskRegression.

32. Selig L, Kritski AL, Cascão AM, Braga JU, Trajman A, Carvalho RMG de. Proposta de vigilância de óbitos por tuberculose em sistemas de informação. Rev Saude Publica. 2010;44:1072-8.

33. Duarte EC, Bierrenbach AL, Barbosa da Silva JJ, Tauil PL, de Fatima Duarte E. Factors associated with deaths among pulmonary tuberculosis patients: a case-control study with secondary data. J Epidemiol Community Health. 2009;63:233-8.

34. Shuldiner J, Leventhal A, Chemtob D, Mor Z. Mortality of tuberculosis patients during treatment in Israel, 2000-2010. Int J Tuberc Lung Dis. 2014;18:818-23.

35. Dale K, Tay E, Trevan P, Denholm JT. Mortality among tuberculosis cases in Victoria, 2002-2013: case fatality and factors associated with death. Int J Tuberc Lung Dis. 2016;20:515-23.

36. Onifade DA, Bayer AM, Montoya R, Haro M, Alva J, Franco J, et al. Gender-related factors influencing tuberculosis control in shantytowns: A qualitative study. BMC Public Health. 2010;10. 
37. Holmes CB, Hausler H, Nunn P. A review of sex differences in the epidemiology of tuberculosis. Int $\mathrm{J}$ Tuberc Lung Dis. 1998;2:96-104.

38. Long NH, Johansson E, Diwan VK, Winkvist A. Different tuberculosis in men and women: beliefs from focus groups in Vietnam. Soc Sci Med. 1999;49:815-22.

39. Heunis JC, Kigozi NG, Chikobvu P, Botha S, van Rensburg HD. Risk factors for mortality in TB patients: a 10-year electronic record review in a South African province. BMC Public Health. 2017;17:38.

40. De Viana PVS, Gonçalves MJF, Basta PC. Ethnic and Racial Inequalities in Notified Cases of Tuberculosis in Brazil. PLoS One. 2016;11.

41. Belo EN, Douglas J, Orellana Y, Levino A, Basta C. Tuberculose nos municípios amazonenses da fronteira Brasil-Colômbia-Peru-Venezuela: situação epidemiológica e fatores associados ao abandono. Rev Panam Salud Publica. 2013;34:321-9.

42. Basta PC, Marques M, Oliveira RL, Cunha EAT, Resendes AP da C, Souza-Santos R. Desigualdades sociais e tuberculose: Uma análise segundo raça/cor no Mato Grosso do Sul. Rev Saude Publica. 2013.

43. Melo T, Resendes AP da C, Souza-Santos R, Basta PC. Distribuição espacial e temporal da tuberculose em indígenas e não indígenas de Rondônia, Amazônia Ocidental, Brasil. Cad Saude Publica. 2012;28:267-80.

44. Hone T, Rasella D, Barreto ML, Majeed A, Millett C. Association between expansion of primary healthcare and racial inequalities in mortality amenable to primary care in Brazil: A national longitudinal analysis. PLoS Med. 2017;14:1-19.

45. Cain KP, Anekthananon T, Burapat C, Akksilp S, Mankhatitham W, Srinak C, et al. Causes of death in HIV-infected persons who have tuberculosis, Thailand. Emerg Infect Dis. 2009;15:258-64.

46. Chang CC, Crane M, Zhou J, Mina M, Post JJ, Cameron BA, et al. HIV and co-infections. Immunol Rev. 2013;254:114-42.

47. Dooley KE, Chaisson RE. Tuberculosis and diabetes mellitus: convergence of two epidemics. Lancet Infect Dis. 2009;9:737-46.

48. Oursler KK, Moore RD, Bishai WR, Harrington SM, Pope DS, Chaisson RE. Survival of patients with pulmonary tuberculosis: clinical and molecular epidemiologic factors. Clin Infect Dis. 2002;34:7529.

49. Baker MA, Harries AD, Jeon CY, Hart JE, Kapur A, Lonnroth K, et al. The impact of diabetes on tuberculosis treatment outcomes: a systematic review. BMC Med. 2011;9:81.

50. Uplekar M, Weil D, Lonnroth K, Jaramillo E, Lienhardt C, Dias HM, et al. WHO's new end TB strategy. Lancet. 2015;385:1799-801.

51. Garcia LP, Freitas LRS de. Consumo abusivo de álcool no Brasil: resultados da Pesquisa Nacional de Saúde 2013. Epidemiol e Serviços Saúde. 2015;24:227-37. 
52. Volkmann T, Moonan PK, Miramontes R, Oeltmann JE. Excess Alcohol Use and Death among Tuberculosis Patients in the United States, 1997-2012. J Tuberc Res. 2016;4:18-22.

53. Lönnroth K, Williams BG, Stadlin S, Jaramillo E, Dye C. Alcohol use as a risk factor for tuberculosis a systematic review. BMC Public Health. 2008;8:289.

54. Rocha MS, Oliveira GP, Aguiar FP, Saraceni V, Pinheiro RS. Do que morrem os pacientes com tuberculose: causas múltiplas de morte de uma coorte de casos notificados e uma proposta de investigação de causas presumíveis. Cad Saúde Coletiva. 2015;31:709-21.

55. Façanha MC. Tuberculose: subnotificação de casos que evoluíram para o óbito em Fortaleza-CE. Rev Bras Epidemiol. 2005;8:25-30.

56. Oliveira GP De, Pinheiro RS, Coeli CM, Barreira D, Codenotti SB. Uso do sistema de informação sobre mortalidade para identificar subnotificação de casos de tuberculose no Brasil. Rev Bras Epidemiol. 2012;15:468-77.

57. Eang MT, Satha P, Yadav RP, Morishita F, Nishikiori N, Van-Maaren P, et al. Early detection of tuberculosis through community-based active case finding in Cambodia. BMC Public Health. 2012;12:1.

\section{Tables}


Table 1: Sociodemographic and clinical characteristics of study participants, Brazil, 2008 to 2013. 


\begin{tabular}{|c|c|c|c|c|c|c|c|c|c|c|}
\hline \multirow{3}{*}{$\begin{array}{l}\text { Variables } \\
\text { Follow-up time in } \\
\text { days }^{\mathrm{a}} \\
\text { Sex }\end{array}$} & \multicolumn{2}{|c|}{ Censoring } & \multicolumn{2}{|c|}{$\begin{array}{l}\text { Death due to } \\
\text { TB }\end{array}$} & \multicolumn{2}{|c|}{$\begin{array}{c}\text { Associated TB } \\
\text { death }\end{array}$} & \multicolumn{2}{|c|}{$\begin{array}{c}\text { Death with no } \\
\text { mention TB }\end{array}$} & \multicolumn{2}{|c|}{ Total } \\
\hline & \multicolumn{2}{|c|}{$\begin{array}{c}1,450 \\
(1,079-1,817)\end{array}$} & \multicolumn{2}{|c|}{$27(5-126)$} & \multicolumn{2}{|c|}{$52(9-196)$} & \multicolumn{2}{|c|}{383,5 (73-876 } & \multicolumn{2}{|c|}{$\begin{array}{c}1,348 \\
(949-1,761) \\
\end{array}$} \\
\hline & $\mathrm{n}$ & $\%$ & $\mathrm{n}$ & $\%$ & $\mathrm{n}$ & $\%$ & $\mathrm{n}$ & $\%$ & $\mathrm{n}$ & $\%$ \\
\hline Male & 157,455 & 84.3 & 6,729 & 3.6 & 2,306 & 1.2 & 20,287 & 10.9 & 186,777 & 65.9 \\
\hline Female & 86,056 & 89.0 & 2,207 & 2.3 & 1,059 & 1.1 & 7,409 & 7.7 & 96,731 & 34.1 \\
\hline \multicolumn{11}{|l|}{ Age group (years) } \\
\hline 0 a 19 & 25,930 & 96.2 & 243 & 0.9 & 71 & 0.3 & 699 & 2.6 & 26,943 & 9.5 \\
\hline 20 a 39 & 115,640 & 91.6 & 1,693 & 1.3 & 1,631 & 1.3 & 7,341 & 5.8 & 126,305 & 44.5 \\
\hline 40 a 59 & 76,544 & 82.8 & 3,620 & 3.9 & 1,342 & 1.5 & 10,941 & 11.8 & 92,447 & 32.6 \\
\hline $60+$ & 25,397 & 67.2 & 3,380 & 8.9 & 321 & 0.8 & 8,715 & 23.0 & 37,813 & 13.4 \\
\hline \multicolumn{11}{|l|}{ Schooling } \\
\hline Illiterate & 16,112 & 81.0 & 1,029 & 5.2 & 174 & 0.9 & 2,566 & 12.9 & 19,881 & 7.0 \\
\hline Less 8 years & 91,104 & 85.6 & 3,192 & 3.0 & 1,346 & 1.3 & 10,787 & 10.1 & 106,429 & 37.5 \\
\hline Greater 8 years & 46,369 & 92.5 & 560 & 1.1 & 343 & 0.7 & 2,837 & 5.7 & 50,109 & 17.7 \\
\hline Ignored & 89,926 & 84.0 & 4,155 & 3.9 & 1,502 & 1.4 & 11,506 & 10.7 & 107,089 & 37.8 \\
\hline \multicolumn{11}{|l|}{ Color or race } \\
\hline White & 83,321 & 85.3 & 2,885 & 3,0 & 1,157 & 1.2 & 10,268 & 10.5 & 97,631 & 34.4 \\
\hline Black & 30,569 & 85.2 & 1,187 & 3,3 & 541 & 1.5 & 3,580 & 10.0 & 35,877 & 12.6 \\
\hline Brown & 98,499 & 86.8 & 3,578 & 3,2 & 1,227 & 1.1 & 10,168 & 9.0 & 113,472 & 40.0 \\
\hline Yellow & 2,336 & 87.2 & 85 & 3,2 & 21 & 0.8 & 238 & 8.9 & 2,680 & 0.9 \\
\hline Indigenous & 2,941 & 91.6 & 89 & 2,8 & 11 & 0.3 & 171 & 5.3 & 3,212 & 1.1 \\
\hline Ignored & 25,845 & 84.4 & 1,112 & 3,6 & 408 & 1.3 & 3,271 & 10.7 & 30,636 & 10.8 \\
\hline \multicolumn{11}{|l|}{ Region } \\
\hline North & 25,123 & 88.2 & 727 & 2.6 & 232 & 0.8 & 2,409 & 8.5 & 28,491 & 10.1 \\
\hline Northeast & 67,368 & 86.9 & 2,560 & 3.3 & 611 & 0.8 & 6,964 & 9.0 & 77,503 & 27.3 \\
\hline Southeast & 111,411 & 85.8 & 4,153 & 3.2 & 1,563 & 1.2 & 12,747 & 9.8 & 129,874 & 45.8 \\
\hline South & 29,231 & 83.0 & 1,048 & 3.0 & 775 & 2.2 & 4,143 & 11.8 & 35,197 & 12.4 \\
\hline Central-West & 10,378 & 83.4 & 448 & 3.6 & 184 & 1.5 & 1,433 & 11.5 & 12,443 & 4.4 \\
\hline \multicolumn{11}{|l|}{$\begin{array}{l}\text { Number of } \\
\text { treatments }\end{array}$} \\
\hline 1 & 234,851 & 86.1 & 8,514 & 3.1 & 3,065 & 1.1 & 26,473 & 9.7 & 272,903 & 96.3 \\
\hline 2 a 3 & 8,473 & 81.8 & 404 & 3.9 & 283 & 2.7 & 1,198 & 11.6 & 10,358 & 3.7 \\
\hline 4 or more & 187 & 75.7 & 18 & 7.3 & 17 & 6.9 & 25 & 10.1 & 247 & 0.1 \\
\hline \multicolumn{11}{|l|}{ Clinical form } \\
\hline Pulmonary & 202,510 & 86.6 & 7,640 & 3.3 & 2,227 & 1.0 & 21,603 & 9.2 & 233,980 & 82.5 \\
\hline Extrapulmonary & 34,191 & 84.8 & 876 & 2.2 & 654 & 1.6 & 4,581 & 11.4 & 40,302 & 14.2 \\
\hline Mixed forms & 6,810 & 73.8 & 420 & 4.6 & 484 & 5.2 & 1,512 & 16.4 & 9,226 & 3.3 \\
\hline \multicolumn{11}{|l|}{ HIV serology } \\
\hline Positive & 17,442 & 64.9 & 319 & 1.2 & 2,703 & 10.1 & 6391 & 23.8 & 26,855 & 9.5 \\
\hline Negative & 127,027 & 90.1 & 3,453 & 2.4 & 251 & 0.2 & 10211 & 7.2 & 140,942 & 49.7 \\
\hline In progress & 20,663 & 88.6 & 655 & 2.8 & 92 & 0.4 & 1901 & 8.2 & 23,311 & 8.2 \\
\hline Not performed & 78,379 & 84.8 & 4,509 & 4.9 & 319 & 0.3 & 9193 & 9.9 & 92,400 & 32.6 \\
\hline \multicolumn{11}{|l|}{ Alcoholism } \\
\hline Yes & 30,302 & 79.0 & 2,241 & 5.8 & 669 & 1.7 & 5,126 & 13.4 & 38,338 & 13.5 \\
\hline No & 213,209 & 87.0 & 6,695 & 2.7 & 2,696 & 1.1 & 22,570 & 9.2 & 245,170 & 86.5 \\
\hline \multicolumn{11}{|l|}{ Diabetes } \\
\hline Yes & 13,174 & 78.2 & 826 & 4.9 & 122 & 0.7 & 2,718 & 16.1 & 16,840 & 5.9 \\
\hline
\end{tabular}


${ }^{a}$ median (IR) 
Table 2: Fine-Gray final model with the ratios of risk sub-distributions (sHR) and confidence interval (CI 95\%) of reported cases of tuberculosis according to different causes of deaths, Brazil, 2008 to 2013.

\begin{tabular}{|c|c|c|c|c|c|c|}
\hline \multirow{2}{*}{$\begin{array}{l}\text { Cause of death } \\
\text { Variables }\end{array}$} & \multicolumn{2}{|c|}{ Death due to TB } & \multicolumn{2}{|c|}{ Associated TB death } & \multicolumn{2}{|c|}{ Death with no mention TB } \\
\hline & $\mathrm{sHR}^{\mathrm{a}}$ & IC $95 \%$ & sHR & IC $95 \%$ & sHR & IC $95 \%$ \\
\hline \multicolumn{7}{|l|}{ Sex } \\
\hline Male & 1.33 & $1.26-1.40^{* * *}$ & 0.94 & $0.87-1.01$ & 1.29 & $1.25-1.32^{* * *}$ \\
\hline Female & Ref e & & Ref & & Ref & \\
\hline \multicolumn{7}{|l|}{ Age group (years) } \\
\hline 0 a 19 & Ref & & Ref & & Ref & \\
\hline 20 a 39 & 1.53 & $1.34-1.76^{* * *}$ & 2.09 & $1.64-2.66^{* * *}$ & 1.89 & $1.74-2.03^{* * *}$ \\
\hline 40 a 59 & 3.95 & $3.46-4.50 * * *$ & 2.53 & $1.98-3.22^{* * *}$ & 3.87 & $3.58-4.18^{* * *}$ \\
\hline $60+$ & 9.29 & $8.15-10.60 * * *$ & 4.26 & $3.29-5.52^{* * *}$ & 10.36 & $9.59-11.20 * * *$ \\
\hline \multicolumn{7}{|l|}{ Schooling } \\
\hline Illiterate & 2.33 & $2.09-2.59 * * *$ & 1.72 & $1.43-2.08^{* * *}$ & 1.64 & $1.55-1.73^{* * *}$ \\
\hline Less 8 years & 1.74 & $1.59-1.91^{* * *}$ & 1.56 & $1.38-1.76^{* * *}$ & 1.41 & $1.35-1.47^{* * *}$ \\
\hline Greater 8 years & Ref & & Ref & & Ref & \\
\hline Ignored & 2.57 & $2.35-2.81^{* * *}$ & 1.73 & $1.53-1.96 * * *$ & 1.58 & $1.51-1.65^{* * *}$ \\
\hline \multicolumn{7}{|l|}{ Color or race } \\
\hline White & Ref & & Ref & & Ref & \\
\hline Black & 1.10 & $1.02-1.18^{* *}$ & 1.29 & $1.16-1.43^{* * *}$ & 0.98 & $0.94-1.01$ \\
\hline Brown & 1.13 & $1.07-1.19 * * *$ & 1.24 & $1.13-1.35^{* * *}$ & 0.96 & 0.93-0.99*** \\
\hline Yellow & 1.01 & $0.82-1.26$ & 1.22 & $0.79-1.89$ & 0.92 & $0.80-1.04$ \\
\hline Indigenous & 0.96 & $0.77-1.19$ & 0.70 & $0.39-1.28$ & 0.59 & $0,51-0,69 * * *$ \\
\hline Ignored & 1.07 & $0.99-1.16$ & 1.18 & $1.05-1.33^{* *}$ & 0.99 & $0.95-1.03$ \\
\hline \multicolumn{7}{|l|}{ Region } \\
\hline North & 0.81 & $0.75-0.89 * * *$ & 0.85 & $0.73-0.98^{*}$ & 0,95 & $0.91-1.00$ \\
\hline Northeast & 0.84 & $0.80-0.89 * * *$ & 0.85 & $0.77-0.94^{* *}$ & 0,89 & $0.86-0.92^{* * *}$ \\
\hline Southeast & Ref & & Ref & & Ref & \\
\hline South & 1.19 & $1.10-1.28^{* * *}$ & 1.21 & $1.10-1.34^{* * *}$ & 1,08 & $1.04-1.12^{* * *}$ \\
\hline Central-West & 1.07 & $0.97-1.64$ & 1.40 & $1.20-1.64^{* * *}$ & 1,16 & $1.10-1.23^{* * *}$ \\
\hline \multicolumn{7}{|l|}{ Clinical form } \\
\hline Pulmonary & Ref & & Ref & & Ref & \\
\hline Extrapulmonary & 0.82 & $0.76-0.88^{* * *}$ & 0.92 & $0.85-1.01$ & 1.15 & $1.11-1.19^{* * *}$ \\
\hline Mixed forms & 1.91 & $1.73-2.11^{* * *}$ & 1.62 & $1.46-1.79 * * *$ & 1.41 & $1.34-1.49 * * *$ \\
\hline \multicolumn{7}{|l|}{ HIV serology } \\
\hline Positive & 0.59 & $0.53-0.67 * * *$ & 62.78 & $55.01-71.63 * * *$ & 4.44 & $4.29-4.58^{* * *}$ \\
\hline Negative & Ref & & Ref & & Ref & \\
\hline In progress & 1.17 & $1.08-1.28^{* * *}$ & 2.27 & $1.78-2.88^{* * *}$ & 1.11 & $1.05-1.16^{* * *}$ \\
\hline Not performed & 2.00 & $1.91-2.10^{* * *}$ & 2.01 & $1.70-2.38^{* * *}$ & 1.31 & $1.27-1.35^{* * *}$ \\
\hline \multicolumn{7}{|l|}{ Alcoholism } \\
\hline Yes & 1.90 & $1.81-2.00 * * *$ & 1.38 & $1.27-1.51^{* * *}$ & 1.35 & $1.31-1.38 * * *$ \\
\hline No & Ref & & Ref & & Ref & \\
\hline
\end{tabular}

Ref: Reference category, ${ }^{* * *} p$-valor $<0.001,{ }^{* *} p$-valor $<0.01,{ }^{*} p$-valor $<0.05,{ }^{a}$ as mentioned in the methods. 


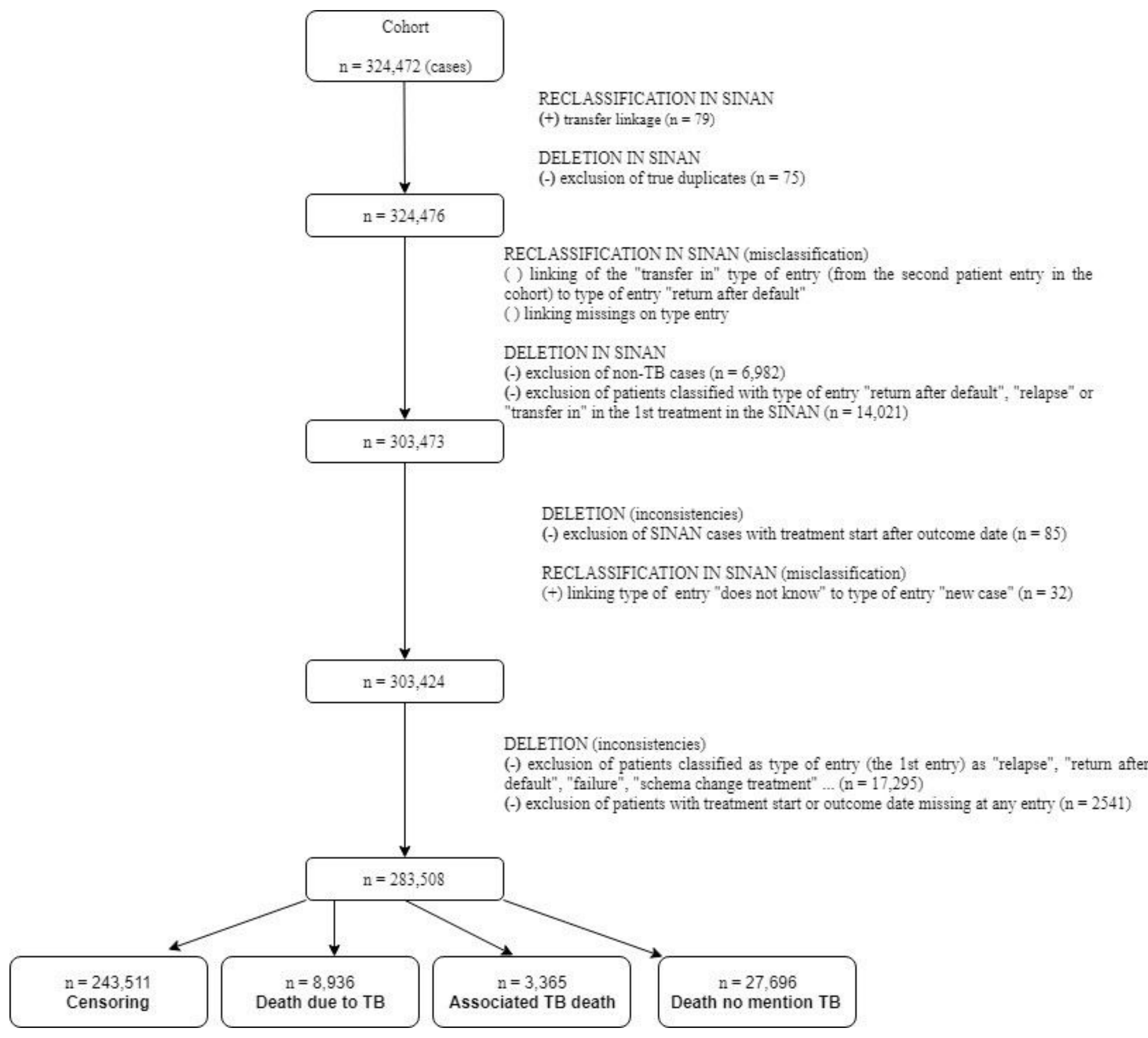

\section{Figure 1}

Flowchart illustrating the selection of tuberculosis cases in Brazil, 2008 to 2013. 


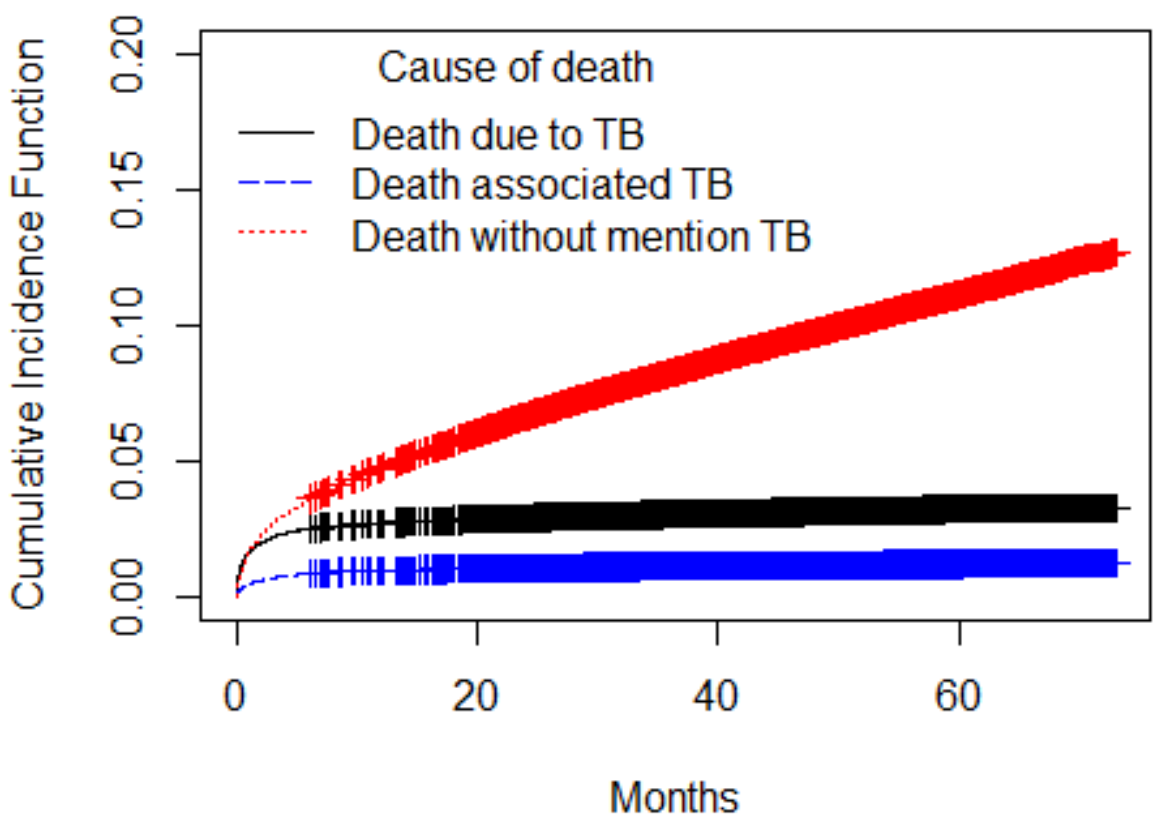

Figure 2

Survival curves estimated by the cumulative incidence functions (CIF) of the sub-distributions of risks proposed by Fine-Gray of the deaths. 